\title{
Nruhari Das on Material Culture and Krishna Consciousness
}

\section{Interviewed by Ashley Makar}

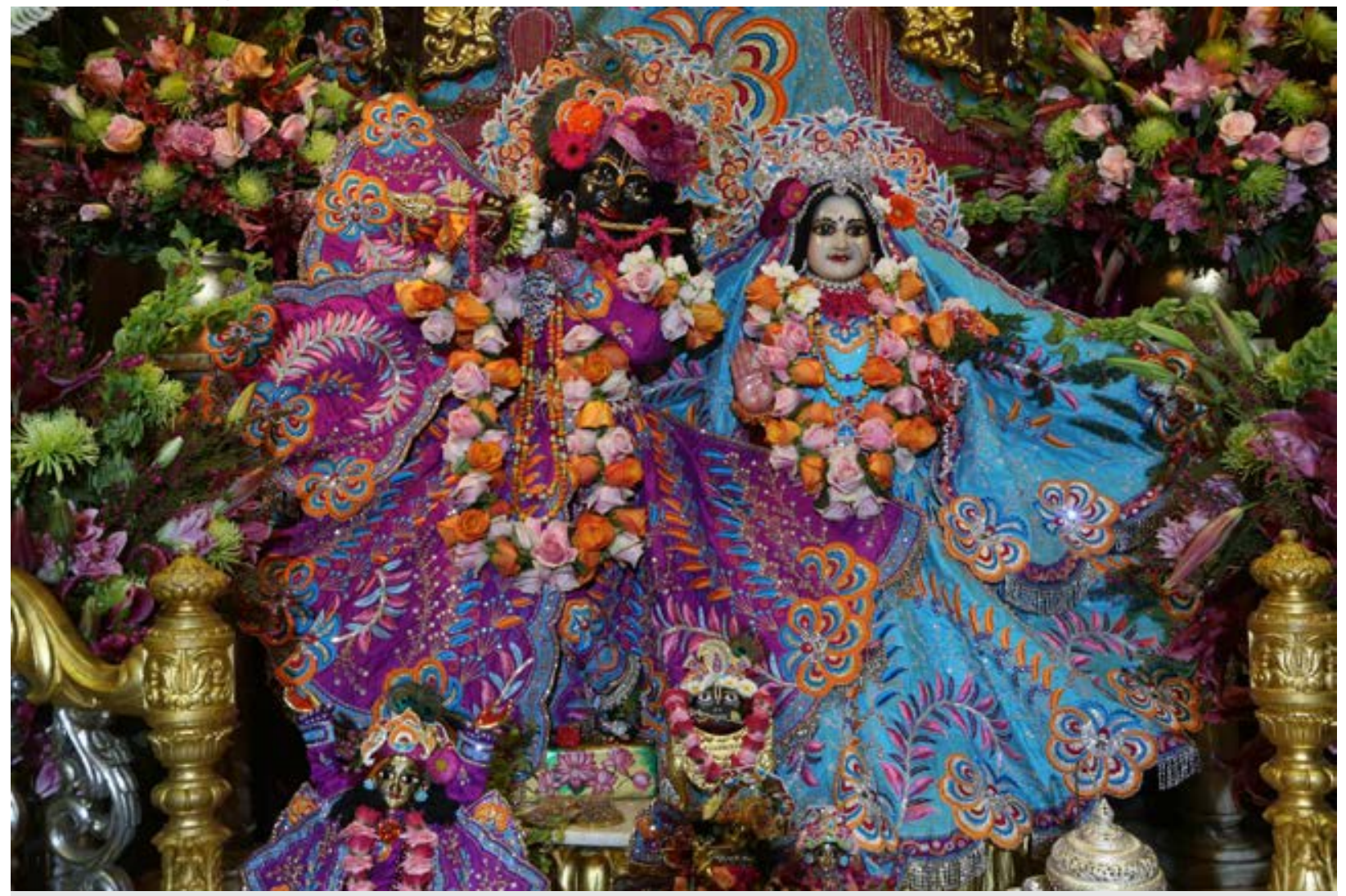

Deity Images of the New York City ISKON Temple

Ashley Makar interviewed Nruhari Das on September 22, 2012 at the Sri Sri Radha Govinda Mandir ISKON Hare Krisha Temple in Brooklyn, New York.

Ashley Makar: In the material world, how do images and objects, for example icons or statues, facilitate our access to the spiritual?

Nruhari Das: That's a very good question. You see, we say that everything you see actually is spiritual, so spiritual/material depends on consciousness. Someone who is spiritually conscious, he sees everything spiritual, he connects with God. But someone who is materialist he believes everything that has no connection with God. Sometimes people say [to me], "Oh you say you are spiritualist, why are you using all those things?" You use cars, they think that this is not part of God. That's the whole trouble. But we spiritualists we say everything belongs to God. And God isn't created, he has unlimited ability to create things in different ways and with different uses, water, this and that, it is all part of the God creation, nothing is really material.

Ashley Makar: What about sacred objects though? 
Nruhari Das: I'm coming to that point. When you say these "icons," we call these deities, but there is a difference between a statue and the deities. God is so inconceivably powerful and he owns everything and he can do what he likes, he can do and undo things, so, the deity, when that form is carved at first it is not spiritual. Why I say it is not spiritual? Because we have to perform certain rituals so that the lord accepts that form. And at that time, it's spiritual.

An atheist or somebody who is not knowledgeable, he will say, "Oh it's a beautiful statue, made of marble or wood or whatever." He has his vision, but me, or any devotee who has been trained, he has the spiritual vision and sees the form no different from the Godhead. Like if I have your picture, a proper picture of you, in a subtle way I know this is you, I don't see the picture only, I see you. When I see your picture, I say, "This is Ashley." I know it's a picture, but at the same time it's connected to you. I see you, because you look like that. So similarly when a deity, or the form which has been carved, it now becomes authorized, we perform the ritual. And the pure devotees [who] know how to do that properly, they call the Lord to come and accept that form. That's no more material. And that's why we're worshiping that form. Because the lord is there, and he can accept that form. He is omnipotent he can say, "Yes, I accept this form, now I'm within this form, and whatever you do you can speak to me, you can offer incense to me, you can pray to me, I accept it. I can listen to you."

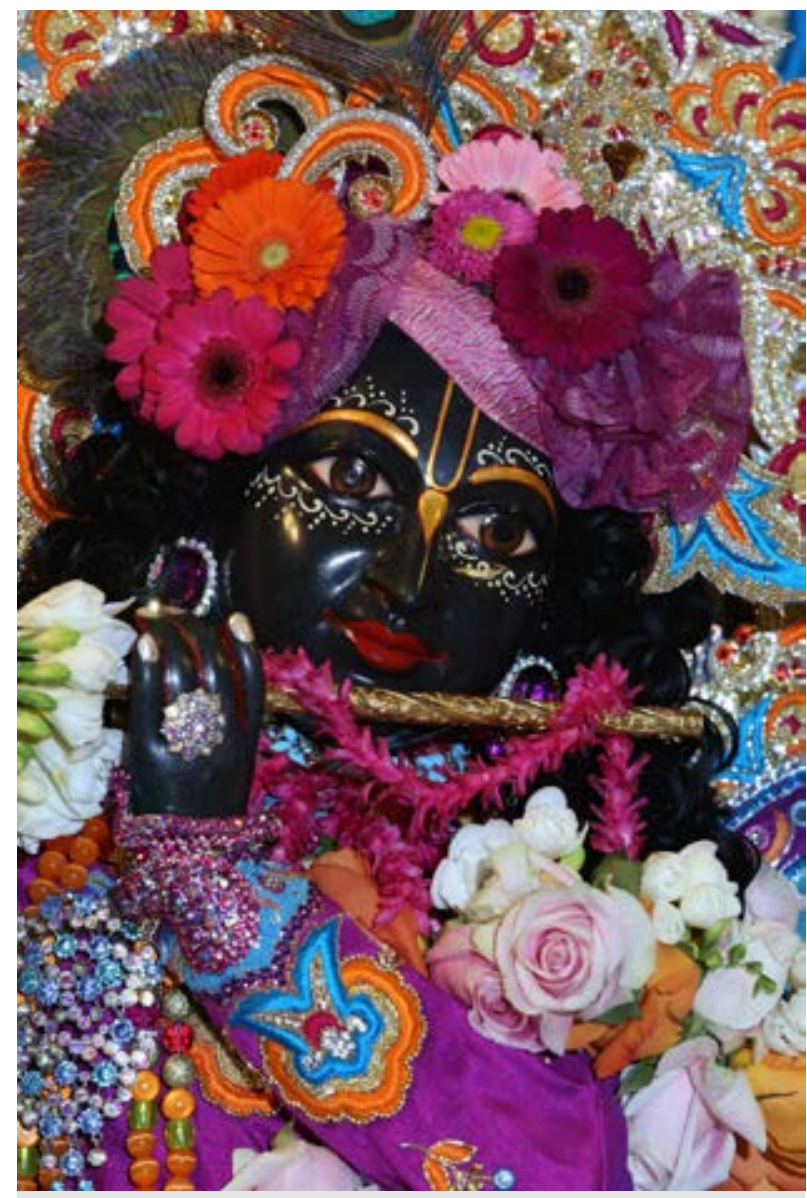

Deity Image of Krishna from the New York City ISKON Temple 
Ashley Makar (referring to the image of Krishna on the temple altar): And once you've done the ritual and the lord accepts and comes there, then it becomes a deity. So the one there is a deity?

Nruhari Das: Yes. That is the Lord, no different from him. We can speak to him. In the beginning stage, you can speak but you can't hear him speaking to you. But as you make spiritual advancement you can actually speak to him like the way you are speaking to me.

The deity is the merciful form of the Lord. It is called the merciful form of the Lord, [because it allows] anybody to offer some service to him. For instance, whether you bow down, you offer prayers, you offer respect, just like if you go see a king, you show respect to the deities, you bow down. We cook, we put them to rest, we worship them, we cook food for them and at lunchtime we offer it to them. By so doing, your consciousness becomes gradually purified. The Lord is there in that form. Whenever you offer something it comes back. He eats.

Ashley Makar: I noticed when I came on Friday [to the temple] at the end of the ceremony there was that table with something on it and at the end they give you the soft sweets-is that the puja offering?

Nruhari Das: We call that prasad. Prasad means everything that you offer to the Lord, and we take the remnant. Prasad means mercy. The Lord, as he is inconceivable, he doesn't eat like us, but he can eat by seeing what you offer to him, by smelling. So he doesn't empty the plate. This is an inconceivable thing. ${ }^{1}$

Ashley Makar: And you said something about putting the Lord to rest?

Nruhari Das: Just like you serve someone, a loved one, you can develop a parental relationship [with the deity]. You see the deities there [in the temple], they are big sized and small sized, and the small size deities have a bed. At nighttime we undress them, we put them in nice dress, we put them to rest, we massage them, just like you put a baby to bed. Amazing experience. We put them to bed. We say, "Okay, go to sleep now," we cover them. In the morning, when it is time, you come, offer some prayers, you clean yourself with some prayers, then go ring the little tiny bell, "Ding, ding, ding! Oh please wake up my dear Lord!"

In spiritual life there is no limitation. You can do things by meditation; some pure devotees can witness the Lord just by meditation. You can think of somebody and when you think of someone intensely that person is also thinking of you. Subtle connection. So meditation means that if you develop a supreme relationship with the supreme Lord as a master, as a friend, as a son, all the relationships we experience in the material world, parental relationship, like father or mother, and the child, friend relationship, master-servant relationship, and lover relationship, loving relationship like conjugal relationship. All these things are here just imitating the reality in the spiritual world. See 
in the spiritual world God has his devotees and he is in interaction with them. Some they love him as a son: God has a mother, his mother Yashoda, his father, Nanda ... Krishna has a girlfriend or wife called Radhani ... he has so many places of worship as supreme Lord, so he's got servants like a king, kingly worship and in other places he is just like an ordinary person, interacting with friends, playing with his friends, his girlfriend sometimes is scolding, you know like a girlfriend and boyfriend they get into arguments.

Ashley Makar: Is that a relationship among the deities or can the devotee have that kind of relationship with the deity?

Nruhari Das: He can. He can develop [that kind of relationship]. The deity as I said is a merciful form of the Lord. By worshiping the deities you can develop that kind of relationship gradually. And finally you [will] be transferred in the spiritual world where Krishna is not just a deity, he's a person also. You can see him; you can interact with him. But most people worship the deity in a very respectful way, the deities are there to teach people in general that the supreme Lord is a person and he can be served by anyone. Therefore, generally the deity worship is performed with honor, reverence, respect. You can't just go to the altar and say, "Krishna I love you," [unless] you are really advanced spiritually.

Ashley Makar: So when you put the deities to rest, do you have to be a priest or a monk to do that?

Nruhari Das: Yes, you have to be initiated to that level. We start at low level, and as you make advancement the spiritual authorities know if you have advanced, especially after following strictly all the rules of relations of spiritual life, you get purified. You cannot go on the altar if you're not clean. But cleanliness-anyone can be clean, but you have to have some spiritual advancement, you are recognized as a Brahmin, we call Brahmin the high priest, they can do that.

Ashley Makar: Are you a Brahmin?

Nruhari Das: Yes. I can worship the deities; in fact I have my personal deities. Whenever I travel I have them, the small size.

Ashley Makar: I saw one deity that I really admire. She looks like a woman with red hands. Who is that?

Nruhari Das: You are very lucky to be attracted to him.

Ashley Makar: Oh, it's a man!

Nruhari Das: Yes, he is the Lord himself. But within him, he is not just either male or female, both.

He is the one that came to teach devotion to the whole world. Is Krishna Chaitanya. 
So what we call Krishna Consciousness is after his name. Because his name is Krishna Chaitanya. In Sanskrit, Chaitanya, in English, Consciousness. So Krishna Chaitanya or Krishna Consciousness. To be Krishna Conscious means to follow in his footsteps, the way he taught us and to develop devotion to Krishna. He is the Lord Chaitanya.

Ashley Makar: Can Krishna as a deity smell, hear, taste, see?

Nruhari Das: Yes, everything.

Ashley Makar: You mentioned your personal deities, do you have them in your home?

Nruhari Das: Yes, I have them in my room. It's just like my friends, and so I can do my puja or my worship wherever I am. In fact, I come to the point that actually, when I'm traveling, it's not me, it's they who are traveling, because everything is taking place by their will. I do not consider myself a preacher, I consider that it is the lord Chaitanya and his brother, [because] what I have is not lord Chaitanya alone.

Ashley Makar: Who is the brother?

Nruhari Das: His brother is called Balaram. Balaram is white, Krishna is black. You see in history, when you look carefully in the world, black and white is very significant. When you think of black, you think of white, when you think of white you think of black.

Ashley Makar: Ah, opposites, right.

Nruhari Das: It's originally from spiritual world.

When you study Krishna Consciousness you know so much, so much. As I say, everything originates from spiritual, you find everything connected to the spiritual world. Like what you call ethnicity. Sometimes people do not like each other because of their race, but the spiritual world is different. Here we hate race, but in the spiritual world race is wonderful. So that the brother of Krishna is white and Krishna is black [but] it is said [they are the] same person: he has a white color and he has a black color. What's the problem? No problem, because one person. So therefore when you understand things spiritually, you can understand reality, all your problems solved.

Ashley Makar: When you travel with them how do you take care of them?

Nruhari Das: It depends on the means you have. When you go in India for instance you have certain people who are very very poor, just wandering the street. And you think, "Oh, such a poor guy." They chose to be like that. They look aesthetically poor, but they are the most wealthy people because they have God with them. So they are not interested in material things. And sometimes they carry the deities in their bag and just take a cloth, like a towel [to put the deities in], and tie it up and put it on the shoulder. But I don't do that because I have more facilities. I have a beautiful box, Samsonite, really nice, and I lay something just like mattresses in there, and I put them there 
because they are very precious objects, I put them there, I cover them.

Ashley Makar: Do they cause you trouble at the airport?

Nruhari Das: No, it's funny, sometimes they go through security, yes? Sometimes nothing happens. And sometimes they say, "I want to see what's inside." And you open. Usually I tell them, please don't touch. And believe me, they all respect when I say please don't touch. [I say,] "If you want me to check it it's all right," and they say, "Okay, go on." And some people, when you open they say, "Oh they look so beautiful. Ok, enough."

Ashley Makar: So it's not a big deal.

Nruhari Das: Different reactions. It's incredible. I saw people once who said, “Oh, they look so peaceful." Just by seeing the deities, those people they get purified. It's just a matter of time.

Ashley Makar: Do you think that's the deities' will?

Nruhari Das: Yes. We have this saying: nothing takes place without the will of the Lord. Even a blade of grass cannot shake without his will. So that's why I say Krishna Consciousness is very deep. Most people when they go through hardships or something, [they say], "Why God is doing this to me?” I give an example: suppose you want to go catch a train or a bus, really determined, and then you miss it, for instance. And then what happen to you? You become really upset, but after you learn that that train had an accident, people died. I'm sure most of the flights that crash, people say, "Oh, I would have gone to that flight, but I didn't go. Lucky, lucky me.” So we shouldn't overreact when we get some disappointment. Just be calm and say, "Oh Lord, everything is for your will," and then later it on, it will be revealed why that happened.

Ashley Makar: Have you always been a devotee of Hare Krishna?

Nruhari Das: I joined in my twenties. I grew up Catholic; my parents were very very devoted. They are very very religious people, I thank them a lot. They used to tell me always believe in God. In fact, my mother from a young age she was always helping the nuns. She was working with the nuns. She was in a church.

Ashley Makar: Where?

Nruhari Das: I was born in Africa in the Central African Democratic Republic of Congo, but from a very young age I went to study in Europe, in France, and finally I've been in the UK for the last 26 years.

Ashley Makar: In your childhood, in your Catholic upbringing, can you think of any encounters with objects and images that were significant to you?

Nruhari Das: Yeah, obviously Jesus Christ and Mary, you know the usual images that you 
see in a church. I would say that I was ready to accept the deities because when I first came into contact with Krishna Consciousness I didn't know what it is, like anyone else, but I just accepted it.

Ashley Makar: Immediately?

Nruhari Das: Yes. This is a connection with my past life, obviously. Krishna said in the Bhagavad Gita that if somebody begins the spiritual life in this life, he will pick it up from there [in the next life]. ${ }^{2}$ Whatever we do spiritually is like a permanent bank balance: it never gets exhausted. Anything we do in the material world finishes in this body, but anything spiritual we do never perishes.

Ashley Makar: And what was your first encounter with Krishna Consciousness?

Nruhari Das: As I said, I was brought up in a very religious atmosphere. When I was young my parents put me in a boarding school. I actually, I was hoping to become a priest.

Ashley Makar: A Catholic priest? A Catholic boarding school in Congo?

Nruhari Das: Yes, one of the best. I learned so many things, music, everything. Then as I grew up, I finished my secondary school, then I didn't go to university. I liked music, because from a young age I was always interested in music, I was a choirboy and then I learned some instruments, my main instrument was saxophone, I play a bit of piano. When I didn't go to university I went to a school of art where they teach beautiful drama, but I was most interested in music. So after a few years, you know, I didn't really graduate as such, but I had some good level of playing music. So then I opted to become a performer. So I became a professional musician.

Ashley Makar: In Congo?

Nruhari Das: Yes. And then I went to Europe, France mostly.

While I was doing that [and living in France], I discussed many good things with a friend. We talking about no violence, we start talking about vegetarianism. And I started to think, yes, I want to become a vegetarian, but I didn't know how to do it. I just had the feeling that something is wrong about killing other creatures and eating them. Although I don't do it myself directly, but why, you see? That never felt really right.

When this conversation came up he was participating in a kind of an organization about non-violence, ahimsa. He told me we are what we eat, and sometimes we get bodily diseases because of what we eat. Actually, I was having some problems with my skin, and he says, "What's your diet?" I decided okay, I'm going to be vegetarian, partially because of health and partially because I found something wrong with killing other living things and eating them, so no violence, ahimsa. 
"We are what we eat" is true spiritually. You know according to scriptures food has three modes: some food is in a mode of goodness, some food in a mode of passion, some food in a mode of ignorance. So if you are eating food in a mode of goodness, you become very calm, very peaceful, very tolerant, compassionate. Most people like that are very charitable, very kind. When you eat food in the mode of passion, you are a passionate person; obviously, you want to get things done. And for the mode of ignorance, it makes you disinterested in spiritual life, disinterested in subtle things: "Oh, I can't be bothered. Really, it's too deep for me."

So I became strict vegetarian, [but] I didn’t know anything yet about Krishna Consciousness. And one day I was in Paris I had a friend of mine say, "Okay, let's go for a meal." So we went looking for a vegetarian restaurant [and] we ended up in a Hare Krishna restaurant, in central Paris! We didn't know; we just went there. I loved the place. It was nice. There were some pictures of Krishna. At that time I didn't know Krishna, I didn't know what was Krishna Consciousness. From my childhood I was always interested in mysticism, spiritual thing. I didn't know what it was, but I was interested in yoga, transcendence. I was already interested, but I didn't know really what to do about it. I was always attracted to Eastern things, especially India. In my childhood I lived in East Africa, in Kenya. I have some relatives who live there, [and there are] lots of Indians there; they are part of the country, just like Africans. I was attracted to Indian stories of scripture, like karma, Mahabharata, as a child, young boy. So when I went there in that restaurant and the atmosphere was so strange, so nice and I went in and I took my meals, I loved it, it was so delicious, and then they advertised it was pure. I said, "I'm going to be coming here." And then when I was leaving the restaurant they handed me a leaflet with some statement from the scriptures.

So that's the way I read about the Krishna Consciousness. I couldn't sleep. I was so overwhelmed. That reality, the truth revealed to me when I heard the spiritual master writing everything he recorded there in the pamphlet, explaining all the philosophy about karma, what the peace formula is for the society.

So, I said, wow, what knowledge. Up until then, I used to believe in Jesus Christ. I used to read New Testament. But when the spiritual master was obviously just like Jesus Christ, but living. I never knew that a living person can have that knowledge just like Jesus Christ. I was mesmerized and said, "Okay, I'm going to really go deep into this." I went back, I read that, I couldn't sleep, my mind was just wondering, "How can I know more about this?" Then after a few days I went back to the Center and I asked, "You gave me this, can I know more about this?" And they took me to where all the books were displayed. And I said, "Okay, which book can I take to read first?” They told me Bhagavad Gita.

We have several scriptures, but Gita is condensed from all the scriptures, all the scriptures actually are from God, but he spoke Gita to his devotee Arjuna. At the battle, Arjuna was bewildered, he didn't have knowledge of his soul, so Krishna spoke the entire Bhagavad Gita in forty-five minutes, just to summarize the whole knowledge of the Vedas. That's why I say when I read Gita Krishna there summarizes everything you 
want to know. ${ }^{3}$

Ashley Makar: So when you had gone to the music school, and then when you wanted to go deeper into Krishna Consciousness, how did you train yourself? How did you become a priest?

Nruhari Das: Whatever ability you have acquired is because of him. Successful businessman, successful politician, successful artist, all these abilities come from Krishna, so you have to offer back to him. When I understood that, I became a full time practitioner of Krishna Consciousness and I used my musical skill singing for him. Traveling around the world, I can sing, I can do concerts, spiritual concerts.

Ashley Makar: And were you using the saxophone and the piano, or were you using instruments that were more traditional?

Nruhari Das: Everything I use. Traditional instruments like drums with two sides and the cymbals; I play saxophone also, and I sing.

Ashley Makar: And is the singing like the chanting the name of Krishna?

Nruhari Das: Yes, there are so many beautiful poems that have been composed about the spiritual mind, but [the one] we call Hare Krishna is the main the one, hare krishna hare krishna krishna krishna hare hare hare rama hare rama rama rama hare hare. This mantra has unlimited melodies. You can sing so beautiful ragas, we call the different tunes ragas, different tunes that are good for the morning, for when [you] wake up, some ragas for the daytime, some ragas for nighttime when we go to sleep, so many varieties of melodies we can sing with Hare Krishna.

Ashley Makar: And what is the spiritual significance of sound in your worship?

Nruhari Das: Ah, sound is the most important element in all creation. Sound is the most subtle element in the whole creation. Sound is what purifies everything, you cannot make spiritual advancement but through sound.

Ashley Makar: And so you were traveling and using your music to serve Krishna? How did you become a priest?

Nruhari Das: Krishna Consciousness is very scientific, it's not something very sentimental, you [can't] just say, "Oh, you have to believe”! Like when you are born in a particular faith, you must be Muslim or Christian because of your parents, no! Krishna Consciousness, when it started in New York most people who joined Krishna Consciousness were atheists, they were hippies. And they were hippies why? Because they were frustrated. The philosophy of Krishna Consciousness woke them up. They were looking for something, they were into drugs and some came from very well-to-do families, they were rebellious. Then they found out and oh. Krishna Consciousness is something you study very carefully, it's got unlimited knowledge. You don't accept it just 
because of this and that.

Ashley Makar: So you had the experience in which you accepted it, but then you had to study and train to gain the authority.

Nruhari Das: Exactly. When you join everybody has to study Krishna Consciousness, the history of Krishna Consciousness. Many people have no formal education, but by becoming devotees they become very learned, they can defeat every great scientist in learning, because the real knowledge is spiritual knowledge. We get training to understand the philosophy very well. The spiritual master trains you.

Ashley Makar: Who was your spiritual master?

Nruhari Das: My spiritual master is one of the foremost disciples of the Founder-Acharya, he is actually also from India, he appeared in a Brahmin family in India, means he appeared in family of the sages, and from young age, when he was like 6, 7, he knew all the scriptures, they are called pure devotees, they are born like that.

Ashley Makar: And when you were training with him, did you get training about the deities, the objects, the images?

Nruhari Das: Everything, he teaches us everything, you cannot know anything without learning from him. He is the one that tells you everything. He teaches you externally, [but] also from within because a spiritual master is not an ordinary person. If you are very serious to learn you become a disciple in the discipline, just like a school: if you really cooperate nicely with the teacher, if you follow his teaching nicely, you'll be successful.

Ashley Makar: What role do the images and objects in the temple play for you as a spiritual leader in the temple here?

Nruhari Das: I'm the servant of the servant of the servant. I'm the servant of God, everything I do is for his pleasure. When people come I serve people, I take care of people, on his behalf. Everything in the temple is meant for the pleasure of the Lord. People come, we take care of them. Because the Lord is the supreme father we have to make sure that everything is used for his pleasure and when people come, because they are very dear to him, we have to receive them nicely. It's just like you manage a hotel or something like that, you make sure you are doing your reception work nicely!

Ashley Makar: And when you are preaching do you show the image of Krishna?

Nruhari Das: Yes, sometimes, according to the circumstances. Some people don't understand very much the images. You just speak philosophy to them and then gradually if they are more interested [you introduce them to them]. Some people have problem to accept the deities, according to their past. Some people fall in love, they say, oh wow, I love them. 
Ashley Makar: And your clothing and bag and hair, what significance does that have for you?

Nruhari Das: The clothing does not matter really. We wear it because it is like a uniform. You go into Catholic church they where this and that. But this is nothing, I can also preach with regular clothes. Many cases when I travel I am in regular clothes, what matters is my heart, what I know.

Ashley Makar: What about your bag, is that just to carry your belongings?

Nruhari Das: In this bag we have rosaries, just like Christians. It has 108 beads. 108 is an auspicious number.

Ashley Makar: And do you use it in the same way that a Catholic would use rosaries?

Nruhari Das: Yes, but we chant Hare Krishna on top of it, nothing else. Like this: Hare Krishna, Hare Krishna Krishna Krishna Hare Hare ... Hare Ram, Hare Ram Ram Ram Hare Hare . . . Hare Krishna, Hare Krishna Krishna Krishna Hare Hare .. . Hare Ram, Hare Ram Ram Ram Hare Hare .. . Hare Krishna, Hare Krishna Krishna Krishna Hare Hare. Then we go and we chant the whole mantra. Whole mantra consists of sixteen syllables: Hare Krishna, Hare Krishna Krishna Krishna Hare Hare . . . Hare Ram, Hare Ram Ram Ram Hare Hare. That's a full mantra and you chant it on each bead and when you finish you move to the next bead, when you go 108 [times] that's one round.

Ashley Makar: And do you do this throughout the day?

Nruhari Das: Sixteen.

Ashley Makar: Sixteen times a day?

Nruhari Das: That's the minimum, you can chant the whole 24 hours, but because we have to do other things [that isn't always possible]. The minimum recommended that you must do is sixteen rounds. So 108 times sixteen.

Ashley Makar: And you can do it while you are walking, for example?

Nruhari Das: Oh yes. If you can’t hold your beads all the time you don't have to, you can just chant.

Ashley Makar: Can you say it silently? Or do you have to speak it?

Nruhari Das: Oh no, there's no hard and fast rule! It can be silently in your mind. If you go in a crowded train you know you can't go Hare Krishna, Hare Krishna, people say, "What's wrong with this guy!" And you can carry your beads also and so that's why we 
keep this bag, it's just to protect the beads. They are sacred so we should be respectful.

Ashley Makar: Why does the bag have feet [depicted] on it?

Nruhari Das: It is the feet of Krishna and Radharani. In the spiritual consciousness the feet are the most important part of the Lord. We worship the feet.

Ashley Makar: Really? Why is that?

Nruhari Das: Because that is where you receive the most of the Lord. Feet is the most sensitive part. When you go to the altar and you see the Lord, the deities, first you look from the feet and then you look up until the face. When the curtains open you see the Lord, then you look from the feet, and then gradually you worshiping from the feet, the beautiful feet, and then you go up, his thighs, the waist, and then finally you go up to the crown and his face, his smiling face, and then you can also see how he is dressed, you appreciate all the decorations.

Ashley Makar (speaking of the service she attended at the temple): I noticed there was fanning with the peacock? What is the significance of the peacock?

Nruhari Das: The peacock is very dear to Krishna, he is one of Krishna's pets. Krishna loves peacocks very much. Krishna perform his pastimes with his girlfriends, with Radhani, with the peacocks always dancing around, Krishna likes that. And that's why he wears a peacock feather.

Ashley Makar: And is the fanning intended to cool the deities?

Nruhari Das: Yes, fanning someone is a sign of honor. Here in the West we have air conditioning, but formerly you honored a sage, or a wife honored a husband, by fanning. When someone fans you it is very lovely, it gives you pleasure.

Ashley Makar: I noticed a lot of movement [in the service], what's the significance of movement in worshiping Krishna?

Nruhari Das: In spiritual world you see every movement is like a dance, every word is like a song, because dancing and movement is all originating from Krishna, dancing and music is the best thing, you know, even in mature life, everything to do with celebration and joy is always music and dance.

Ashley Makar: What about the fire?

Nruhari Das: We offer all the material elements to the Lord because they all originate from him: we offer fire, water, love, and also incense. Incense represents the earth; Krishna says in the Bhagavad Gita, "Earth, water, fire, air, ether, they are all my energies." So, in order to please the Lord we offer those things. 
Ashley Makar: And after the fire was with the deity they bring it to the people and they were warming their hands.

Nruhari Das: Exactly. Why we do that? When it has been offered to the Lord it becomes prasad, mercy. So that's mercy you are accepting. This has been honored by the Lord, offered to the Lord, now it's come to me as his mercy, so I must take it. That's the way you make spiritual advancement.

Ashley Makar: And the garlands and flowers?

Nruhari Das: Anything that has been used by the Lord we accept it as a remnant because it is no different from him.

Ashley Makar: Is there anything you would want to add to this kind of conversation about images and objects?

Nruhari Das: The method of worshiping the deities is not only the priest on the altar. When you come you might not be allowed to be on the altar, but when you come you bow down in front the deity, that is worship. When you accept the items that have been

offered to him, that's also worship. When you come to the temple, you passing by, oh let me go see the Lord, that's all worship, worship doesn't mean you have to be on the altar. Anything you do for the pleasure of the Lord is worship. The meaning of worship is to please the Lord, to give him pleasure, that's the meaning of worship.

Ashley Makar: Thank you for being so generous with your time.

Nruhari Das: You are most welcome. It was a pleasure. Krishna arranged everything, I'm only his instrument.

Watch a video of Nruhari Das leading services here: http://www.radhagovindanyc.com/ video/nruhari-das-leads-sayana-arati-kirtan/

(C) Ashley Makar

\section{Citation Guide}

1. Ashley Makar, "Nruhari Das on Material Culture and Krishna Consciousness," Interview, in MAVCOR Journal 1, no. 1 (2017), doi:10.22332/mav.int.2017.2

Makar, Ashley. "Nruhari Das on Material Culture and Krishna Consciousness." Interview. In MAVCOR Journal 1, no. 1 (2017). doi:10.22332/mav.int.2017.2 


\section{Notes}

1. As Andrea Marion Pinkney describes, prasāda, also called parsād, is a central practice of Hindu devotional ritual in which devotees approach a deity image and "make some kind of offering to the deity-it can be material, such as flowers or fruits, or non-material, such as prayers or praise." Pinkney explains: "Once the ... offering is received by the deity, it is called bhoga, meaning 'tasted, enjoyed.' Following the deity's acceptance of the initial presentation, the offerings ... are considered transvalued and may be returned to the devotee as a blessed token of ritual: this return gift is called prasāda." See Pinkney, "Prasāda, the Gracious Gift, in Contemporary and Classical South Asia," Journal of the American Academy of Religion 81, no. 3 (2013): 736. 10.1093/jaarel/lfto22

2. The Bhagavad Gita is a section of the Hindu Sanskrit epic the Mahabharata in which Krishna, who has been serving as Prince Arjuna's charioteer, reveals himself on the eve of battle and offers his teachings.

3. The Vedas are the oldest texts of Hinduism.

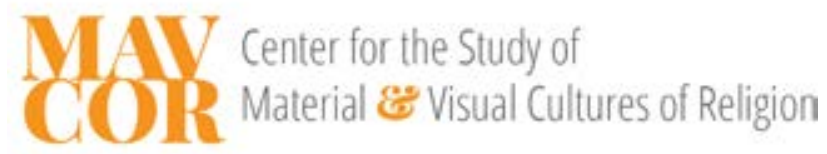

\section{Yale}

Copyright 2016 Yale University All rights reserved.

MAVCOR Journal is a born-digital, double-blind peer-reviewed publication of the Center for the Study of Material and Visual Cultures of Religion at Yale University

(mavcor.yale.edu). 